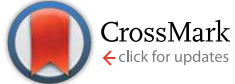

Cite this: RSC Adv., 2015, 5, 82717

Received 6th August 2015

Accepted 24th September 2015

DOI: $10.1039 / \mathrm{c} 5 \mathrm{ra} 15783 \mathrm{~h}$

www.rsc.org/advances

\section{Tailoring the structure and gas permeation properties of silica membranes via binary metal oxides doping}

\begin{abstract}
P. H. Tchoua Ngamou, ${ }^{\star a}$ M. E. Ivanova, ${ }^{a}$ C. Herwartz, ${ }^{\text {b }}$ N. Lühmann, ${ }^{c}$ A. Besmehn, ${ }^{c}$ W. A. Meulenberg, ${ }^{a}$ J. Mayer ${ }^{\text {bd }}$ and O. Guillon ${ }^{a}$

The sol-gel method was employed for the synthesis of binary $\mathrm{X}$-Co ( $\mathrm{X}$ : $\mathrm{Mn}, \mathrm{Cr}$ ) oxide-doped silica membranes with different $\mathrm{X} / \mathrm{Co}$ molar ratios (X/CO: $0.1,0.3,0.9$ ). Single-gas permeation tests were performed at $200^{\circ} \mathrm{C}$ to determine the effect of the binary oxide composition on the amorphous silica network. The X-ray diffraction (XRD), X-ray Photoelectron Spectroscopy (XPS) and Transmission Electron Microscopy (TEM) indicated the presence of smaller $\mathrm{Mn}_{x} \mathrm{CO}_{3-x} \mathrm{O}_{4}$ and $\mathrm{Cr}_{x} \mathrm{CO}_{3-x} \mathrm{O}_{4}$ oxide nanocrystals in the silica matrix in addition to amorphous $\mathrm{Co}, \mathrm{Mn}$ and $\mathrm{Cr}$ species. The $\mathrm{H}_{2} / \mathrm{N}_{2}$ permeance ratio decreased from $(126.3 \pm 9)$ to $(10.7 \pm 2)$ with an increase in X/Co molar ratio from 0.1 to 0.9 due to the formation of larger pores. However, the binary Co-X oxide-doped silica membrane with the lowest $X$ content showed a $\mathrm{H}_{2} / \mathrm{N}_{2}$ permeance ratio, (126.3 \pm 9 ), higher than that, $(63.6 \pm 6)$, of the single cobalt oxide silica membrane. Based on FTIR analysis, it was found that the densification of the membrane at low $\mathrm{X}$ content resulted from the formation of silica structures with narrowed siloxane rings. In contrast, the enlargement of siloxane rings due to favorable condensation reactions occurred at high $\mathrm{X}$ content.
\end{abstract}

\section{Introduction}

Systems based on transition-metal oxide nanoparticles embedded in inorganic oxide matrices are receiving growing interest in innovative technological applications. The combination of the unique properties of the guest phase and the host matrix is at the origin of the discovery of new or improved properties. For example, cobalt oxide nanoparticles dispersed in a high surface area silica matrix represents one of the most investigated functional composite materials thanks to its catalytic $^{1-3}$ and gas/humidity sensing ${ }^{4,5}$ properties. In the field of membrane technology for $\mathrm{H}_{2}$ purification from gas mixtures, embedding cobalt oxide nanoparticles into a silica matrix has been demonstrated to improve both the stability and the separation performance of the silica membrane in presence of steam. ${ }^{6,7}$ The poor hydrothermal stability of silica membranes is ascribed to the rearrangement of the silica structure via

${ }^{a}$ Institute for Energy and Climate Research, IEK-1: Materials Synthesis and Processing, Forschungszentrum Jülich GmbH, 52425 Jülich, Germany. E-mail: p.tchoua@ fz-juelich.de

${ }^{b}$ Central Facility for Electron Microscopy (GFE), RWTH Aachen University, 52056 Aachen, Germany

${ }^{c}$ Central Institute for Engineering, ZEA-3: Analytics, Forschungszentrum Jülich GmbH, 52425 Jülich, Germany

${ }^{d}$ Ernst Ruska-Centre for Microscopy and Spectroscopy with Electrons ER-C, Forschungszentrum Jülich GmbH, D-52425 Jülich, Germany

$\dagger$ Electronic supplementary information (ESI) available. See DOI: 10.1039/c5ra15783h hydrolysis and condensation reactions, which lead to a membrane densification and eventually to the formation of cracks and larger non-selective pores. The presence of dispersed $\mathrm{Co}_{3} \mathrm{O}_{4}$ nanoparticles within the silica framework was believed to shield the silica matrix and inhibit the hydrolysis and condensation of the silica in the pore walls, thereby limiting the structural rearrangement. ${ }^{\mathbf{8} 9}$ This was not the case of $\mathrm{TiO}_{2}, \mathrm{Nb}_{2} \mathrm{O}_{5}$ and $\mathrm{ZrO}_{2}$ oxides, which improve the hydrothermal stability of the silica by stabilizing the porous structure via enhancement of network connectivity. ${ }^{\mathbf{1 0}}$ Cobalt oxide-doped silica membranes have also been demonstrated to be stable in the presence of $\mathrm{H}_{2} \mathrm{~S}^{11}$ as well as in aqueous environments, as for example during the long-term pervaporation dehydration of ethanol-water mixture. ${ }^{12}$ The literature, as above-mentioned, clearly shows that cobalt oxide is the most investigated transition metal oxide in producing metal oxide silica membranes for gas separation. Some attempts have been made with $\mathrm{FeO}_{x}$ but the obtained membranes, although microporous were not suitable for gas separation, ${ }^{\mathbf{1 3}}$ whilst thermally stable oxides such as $\mathrm{CrO}_{x}$ and $\mathrm{MnO}_{x}$ were embedded on SBA-15 mesoporous silica structures for catalytic application. ${ }^{\mathbf{1 4 , 1 5}}$

Very recently, the incorporation of binary metal oxides within the silica framework has been shown to affect the separation properties of the membrane. For example, Ballinger et al. ${ }^{16}$ reported a decrease of gas separation properties of binary palladium-cobalt oxides silica membranes after exposure at $500{ }^{\circ} \mathrm{C}$ in presence of hydrogen. The reduced gas separation 
performance was attributed to the easy reducibility of the palladium oxide to its metallic state, which creates molecular gaps into the silica matrix. In a separate study, ${ }^{17}$ the same authors reported an enhancement of gas separation properties of binary lanthanum-cobalt oxides silica membranes after redox cycling. This improvement of the gas separation properties was ascribed to the closure or collapse of large pore sizes, most likely influenced by the presence of the lanthanum silicate phase. Darmawan et al. ${ }^{\mathbf{1 8}}$ demonstrated that the gas separation properties of iron-cobalt oxide membranes were affected by changing the Fe/Co molar ratio, and enhanced gas permeance and permeation ratios where obtained for $\mathrm{Fe} / \mathrm{Co}=0.1$. However, a correlation between the gas separation properties and the structural parameters was not demonstrated. In fact, the spinel $\mathrm{Co}_{3} \mathrm{O}_{4}$ can accommodate various cations with more than one oxidation state within the available octahedral and tetrahedral sites. This structural tailorability of $\mathrm{Co}_{3} \mathrm{O}_{4}$ has been demonstrated to be at the origin of interesting and tunable properties. ${ }^{19}$ Therefore, the insertion of other transition metal oxides such as $\mathrm{MnO}_{x}$ and $\mathrm{CrO}_{x}$ in the lattice of the spinel $\mathrm{Co}_{3} \mathrm{O}_{4}$ can structurally affect the silica network and hence the separation performance of the membrane.

In this context, the present work aims to investigate the effect of the incorporation of binary metal oxides $\mathrm{X}-\mathrm{Co}(\mathrm{X}=\mathrm{Mn}$, $\mathrm{Cr}$ ) with different compositions into the silica matrix. As the metal oxide concentration into the silica matrix is well-known to affect the membrane performance, ${ }^{6}$ the total metal-to-silicon molar ratio was kept constant during the sols synthesis and only $\mathrm{X} / \mathrm{Co}$ molar ratio was varied. Structural and chemical changes induced by the incorporation these binary oxides were analyzed by means of X-ray diffraction (XRD), X-ray Photoelectron Spectroscopy (XPS), Transmission Electron Microscopy (TEM), Fourier Transform Infrared (FTIR) and discussed together with the single gas permeation results. Furthermore, the gas permeation properties of these binary oxides silica membranes were compared to that of a reference single cobalt oxide silica membrane. Cobalt oxide has been used as one component of the binary metal oxide because it is recognized to improve the hydrothermal stability of the silica membrane. We have decided to concentrate first on the structural modification induced by the insertion of these binary oxides and their influence on the separation performance. The long-term hydrothermal stability of these binary membranes will be investigated in the next step of this research work.

\section{Experimental}

\section{Sol-gel synthesis}

The sol-gel technique was employed for the preparation of binary $\mathrm{X}-\mathrm{Co}(\mathrm{X}=\mathrm{Mn}, \mathrm{Cr})$ metal oxide-doped silica sols with different $\mathrm{X} / \mathrm{Co}$ molar ratios $(\mathrm{X} / \mathrm{Co}=0.1,0.3$ and 0.92$)$, while keeping the total metal-to-silicon ratio constant i.e. $(\mathrm{Co}+\mathrm{X}) / \mathrm{Si}=$ $1: 2$. The acid catalyzed sol-gel method used in this study is a modified version of the procedure previously reported for pure $\mathrm{SiO}_{2}$ by van Gestel et al. ${ }^{20}$ In brief, tetraethylorthosilicate (TEOS) was mixed with ethanol at room temperature and an aqueous solution of nitric acid was added dropwise. The obtained transparent solution was refluxed at $60{ }^{\circ} \mathrm{C}$ for $3 \mathrm{~h}$ to promote hydrolysis and condensation reactions. Then, the corresponding amounts of cobalt nitrate hexahydrate $\left(\mathrm{Co}\left(\mathrm{NO}_{3}\right)_{2} \cdot 6 \mathrm{H}_{2} \mathrm{O}\right)$ and chromium nitrate nonahydrate $\left(\mathrm{Cr}\left(\mathrm{NO}_{3}\right)_{3} \cdot 9 \mathrm{H}_{2} \mathrm{O}\right)$ or cobalt nitrate hexahydrate $\left(\mathrm{Co}\left(\mathrm{NO}_{3}\right)_{2} \cdot 6 \mathrm{H}_{2} \mathrm{O}\right)$ and manganese nitrate tetrahydrate $\left(\mathrm{Mn}\left(\mathrm{NO}_{3}\right)_{2} \cdot 4 \mathrm{H}_{2} \mathrm{O}\right)$ were dissolved in ethanol and added slowly to the transparent solution. The obtained sols were refluxed at $60{ }^{\circ} \mathrm{C}$ for $5 \mathrm{~h}$ and the final molar ratio of different components TEOS: metal nitrate hydrate : EtOH : $\mathrm{H}_{2} \mathrm{O}: \mathrm{HNO}_{3}$ was $2: 1: 7.6: 12.3: 0.09$. During the synthesis, the $(\mathrm{X}+\mathrm{Co}) / \mathrm{Si}$ molar ratio was kept equal to $1: 2$ and $\mathrm{X} / \mathrm{Co}$ molar ratio (hereafter denoted as XCoSi-a where $\mathrm{a}=$ $\mathrm{X} / \mathrm{Co}$ ) was $0: 100 ; 10: 90 ; 25: 75$ and 48/52.

\section{Powder preparation and characterization}

The obtained sols were dried in an oven at $60^{\circ} \mathrm{C}$ for $72 \mathrm{~h}$ to form xerogels. The xerogels samples were ground into a fine powder and fired in air at $600{ }^{\circ} \mathrm{C}$ for $3 \mathrm{~h}$ using a heating/cooling rate of $1{ }^{\circ} \mathrm{C} \mathrm{min}^{-1}$. Several analytical techniques such as XRF, FTIR, XRD, XPS, TEM have been employed for the characterization of the prepared powders. Elemental analysis of the binary metal oxide-doped silica powders were performed by means of a dispersive X-ray fluorescent instrument (Bruker S8 Tiger). Infrared spectroscopy was performed using a Tensor 27 (Bruker Optics) equipped with an DTGS detector and a Golden Gate diamond attenuated total reflectance (ATR) unit containing ZnSe mirrors. The resolution of the spectrometer was set at $4 \mathrm{~cm}^{-1}$ and all spectra were collected in the range $800-4000 \mathrm{~cm}^{-1}$ and normalized to the gradient vector for comparison. The deconvolution of the absorption bands was performed using the "fit multiple peaks" function of the ORIGIN Pro 9.0 software. Only the peak position of the $\mathrm{Si}-\mathrm{OH}$ vibration was fixed at $950 \mathrm{~cm}^{-1}$, while the peak position and peak height of other components were allowed to vary between samples to achieve the best possible fit. A D4 Endeavor Bruker AXS diffractometer with a Kristalloflex $770 \mathrm{X}$-ray generator was used to record the XRD patterns. A Pawley fit using the "Topas 4.2" software was used for the identification of the crystalline phases by referring to the powder XRD database JCPDS-ICDD and the calculation of the lattice parameter, while the crystalline sizes were calculated using the Scherrer equation. X-ray photoelectron spectroscopy (XPS) measurements were performed using a PHI5000 Versa Probe II from ULVAC-PHI Inc., USA, equipped with an Al k-alpha (1.486 KeV) source for excitation in the analysis chamber under high vacuum $\left(1 \times 10^{-8} \mathrm{mbar}\right)$. The sample charging was corrected with respect to the binding energy of the C1s core level (284.6 eV). The peak deconvolution was achieved using the "fit multiple peaks" function of the ORIGIN Pro 9.0 software. The fitting of synthetic components followed the procedures described by Biesinger et al. ${ }^{21}$

The surface and cross-section images of membranes were obtained using a Zeiss ultra 55 scanning emission microscope operating at an accelerating voltage of $15 \mathrm{KV}$. A transmission electron microscope (FEI Tecnai F20) equipped with an EDAX EDX system and a GATAN GIF imaging filter was used for the identification of the morphology and crystal structure of the 
prepared powders. TEM samples were prepared by suspending the powders on a holey carbon grid.

\section{Membrane fabrication and testing}

Prior to dip-coating, the sols were diluted 15 times in ethanol and filtered with a $0.8 \mu \mathrm{m}$ membrane filter (Whatman FP30/0.8CA). A series of 2 mm-thick $\alpha$ - $\mathrm{Al}_{2} \mathrm{O}_{3}$ disk-shaped supports provided by Pervatech BV (39 $\mathrm{mm}$ diameter) were dip-coated with a boehmite sol as describe elsewhere. ${ }^{20}$

After calcination at $600{ }^{\circ} \mathrm{C}$ for $3 \mathrm{~h}$, a $\gamma-\mathrm{Al}_{2} \mathrm{O}_{3}$ intermediate layer with an average pore size of $5 \mathrm{~nm}$ was formed. Binary metal oxide-doped silica membranes were prepared by dipcoating the ceramic supports in ethanol-diluted sols using an automatic dip coater (KSV NIMA). The membrane calcination procedure was identical as for powders. The coating and calcination cycle steps were repeated to increase the film thickness and cover any remaining defects. Gas permeation tests were performed using an in-house made dead-end mode stainless steel module. The gas flow at the feed side of the module was controlled by an accurate pressure controller (Brooks, pressure controller 5866). The gas flow rate at the permeate side was measured using two flow meters with maximum flow of $8 \mathrm{ml}$ $\min ^{-1}$ and $40 \mathrm{ml} \mathrm{min}^{-1}$ (Brooks, smart mass flow).

\section{Discussion and results}

\section{Gas permeation properties of binary metal oxides-doped silica membranes}

Fig. 1 shows a typical SEM image of the surface and crosssection of the manganese-cobalt oxide-doped silica membrane with a Mn/Co molar ratio of 0.9 (named MnCoSi-0.9). A $120 \mathrm{~nm}$ thick and uniform MnCoSi top layer, coated on a $\gamma-\mathrm{Al}_{2} \mathrm{O}_{3}$ interlayer, can clearly be observed. The gas separation performance of sol-gel made CoSi and $\mathrm{XCoSi}(\mathrm{X}=\mathrm{Mn}, \mathrm{Cr}$ ) membranes was evaluated by measuring the permeance at

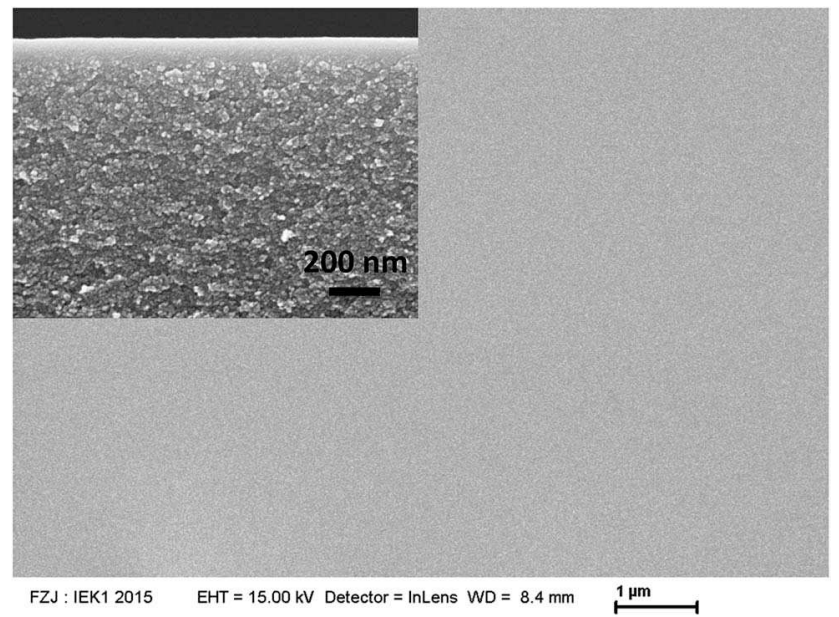

Fig. 1 SEM picture of the MnCoSi-0.1 film top layer. The insert corresponds to the cross-sectional SEM image of the ceramic membrane, showing the intermediate gamma alumina layer and the $120 \mathrm{~nm}$ thick MnCoSi-0.1 top layer.
$200{ }^{\circ} \mathrm{C}$ of several gases with different kinetic diameters. The measured permeance values in addition to $\mathrm{H}_{2} / \mathrm{N}_{2}$ permeance ratios are presented in Fig. $2(\mathrm{a}-\mathrm{c})$ and Table $\mathrm{S} 1$ of the ESI. $\dagger$ A test series of five samples were performed for each membrane with a good reproducibility of gas permeance, thereby confirming the reproducibility of the sol-gel synthesis method. A close examination of gas permeance values displayed in Fig. 2(a-c) indicates that the combination of binary $\mathrm{X}-\mathrm{Co}(\mathrm{X}=\mathrm{Mn}, \mathrm{Cr})$
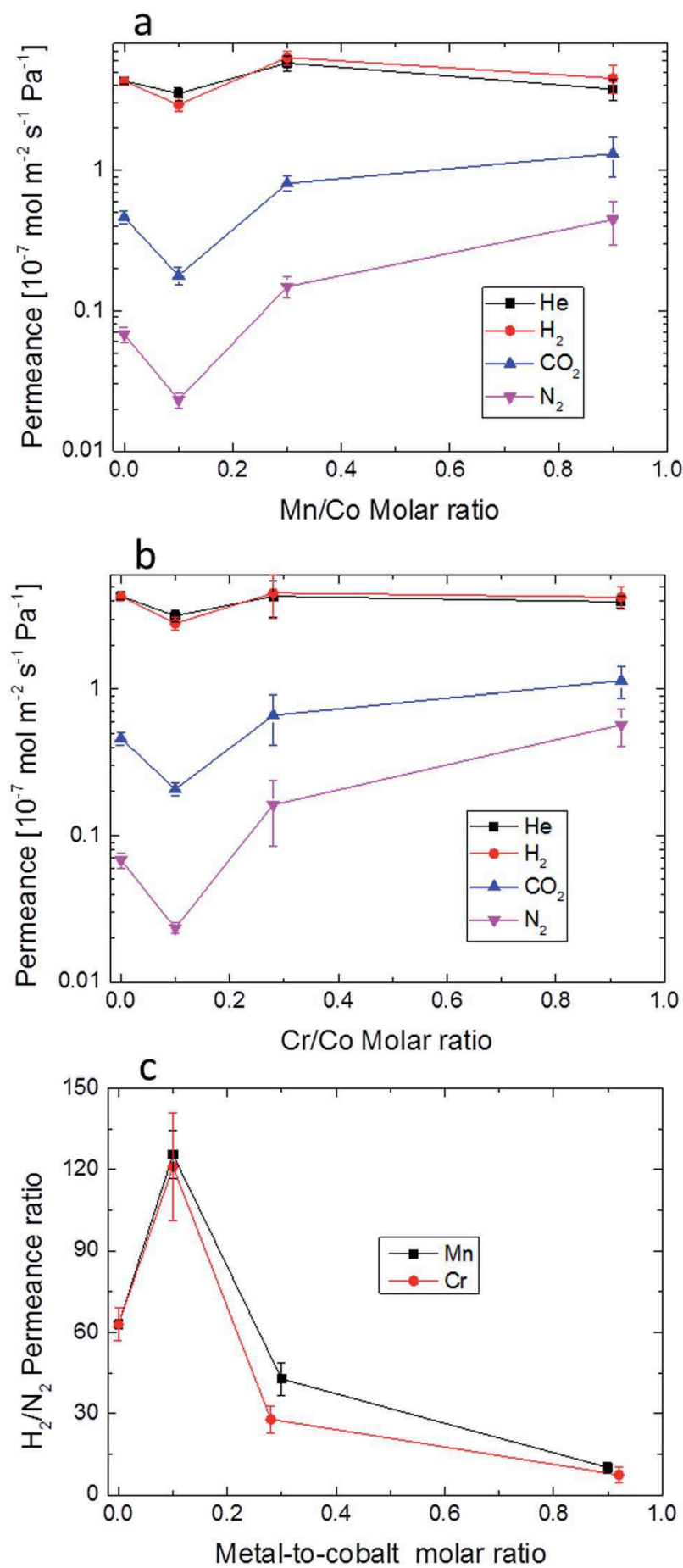

Fig. 2 (a and b) Gas permeance $\left(\mathrm{He}, \mathrm{H}_{2}, \mathrm{CO}_{2}, \mathrm{~N}_{2}\right.$ ) and (b) $\mathrm{H}_{2} / \mathrm{N}_{2}$ permeance ratio as function of the $\mathrm{X} / \mathrm{Co}(\mathrm{X}=\mathrm{Mn}, \mathrm{Co})$ molar ratio. 
oxides into the silica matrix enabled the formation of silica structures with different pores sizes. This was highlighted by the permeance of large gas molecules like $\mathrm{CO}_{2}\left(d_{\mathrm{k}}=0.33 \mathrm{~nm}\right)$ and $\mathrm{N}_{2}\left(d_{\mathrm{k}}=0.36 \mathrm{~nm}\right)$, which increased with an increase in $\mathrm{X}$ content. For example, the $\mathrm{N}_{2}$ permeance increased from $(2.3 \pm$ $0.3) \times 10^{-9} \mathrm{~mol} \mathrm{~m}^{-2} \mathrm{~s}^{-1} \mathrm{~Pa}^{-1}$ to $(4.4 \pm 0.2) \times 10^{-8} \mathrm{~mol} \mathrm{~m}^{-2} \mathrm{~s}^{-1}$ $\mathrm{Pa}^{-1}$ and from $(2.3 \pm 0.2) \times 10^{-9} \mathrm{~mol} \mathrm{~m}^{-2} \mathrm{~s}^{-1} \mathrm{~Pa}^{-1}$ to $(5.7 \pm 0.2)$ $\times 10^{-8} \mathrm{~mol} \mathrm{~m}^{-2} \mathrm{~s}^{-1} \mathrm{~Pa}^{-1}$ as the $\mathrm{Mn} / \mathrm{Co}$ and $\mathrm{Cr} / \mathrm{Co}$ molar ratios increased from 0.1 to 0.9 , respectively. This increase of the $\mathrm{N}_{2}$ permeance for more than one order of magnitude is ascribed to the formation of larger pore sizes.

In contrast, CoSi membrane showed at $200{ }^{\circ} \mathrm{C}$ a $\mathrm{N}_{2}$ permeance of $(6.8 \pm 0.8) \times 10^{-9} \mathrm{~mol} \mathrm{~m}^{-2} \mathrm{~s}^{-1} \mathrm{~Pa}^{-1}$ that is higher than that of XCoSi-0.1 (X $=\mathrm{Mn}, \mathrm{Cr})$ membranes. These results suggest that the densification of the silica membrane takes place at low X content (i.e. X/Co $=0.1$ ), while the formation of larger pores occurs at higher $\mathrm{X}$ content. These findings were confirmed by the behavior of $\mathrm{H}_{2} / \mathrm{N}_{2}$ permeance ratios as a function of the doping content (Fig. 2(c)). For instance, the CoSi membrane showed $\mathrm{H}_{2} / \mathrm{N}_{2}$ permeance ratio of $63.6 \pm 6$ that increased to $126.3 \pm 9$ for MnCoSi-0.1 membrane, while MnCoSi-0.3 and MnCoSi-0.9 membranes showed $\mathrm{H}_{2} / \mathrm{N}_{2}$ permeance ratios of $43.6 \pm 6$ and $10.7 \pm 2$, respectively. The formation of silica structures with different pore sizes when increasing the $\mathrm{X} / \mathrm{Co}$ molar ratio can also be evidenced by the permeance of small molecules like $\mathrm{He}\left(d_{\mathrm{k}}=0.26 \mathrm{~nm}\right)$ and $\mathrm{H}_{2}\left(d_{\mathrm{k}}\right.$ $=0.289 \mathrm{~nm}$ ) as shown in Fig. 2(a) and (b). The permeance of $\mathrm{H}_{2}$ appeared to be slightly lower than that of $\mathrm{He}$ for XCoSi-0.1 membrane and higher than that of $\mathrm{He}$ for XCoSi-03 and XCoSi-0.9 membranes. In fact, when the permeation is governed by an activated permeation mechanism, the permeance of $\mathrm{H}_{2}$ appears lower than that of He due to its high molecular size. In the case of a Knudsen diffusion mechanism, the $\mathrm{H}_{2}$ permeance is higher than that of He due to the difference in molecular weight. This means that increasing the X/Co molar ratio enables the formation of membranes with pores sizes bigger than the molecular size of $\mathrm{H}_{2}$ but still lower than the molecular size of $\mathrm{N}_{2}$. However, low X/Co molar ratio enable the formation of narrower pore sizes than those of the single cobalt oxide-doped silica (CoSi) membrane.

\section{Characterization of binary metal oxides-doped silica gels}

Several characterization techniques have been investigated to understand the changes in the silica matrix induced by the insertion of binary $\mathrm{Co}-\mathrm{Cr}$ and Co-Mn oxides. For the abovementioned investigations, dried gels were prepared by following the same calcination procedure as for membranes.

\section{Quantitative (XRF) analysis}

Quantitative analysis of Co Mn and Cr elements in the CoSi and $\mathrm{XCoSi}$ (X = Mn, Cr) powders were done using dispersive X-ray Fluorescence Spectrometry (XRF). The composition of the sol-gel made powders is reported in Table 1. For instance, $\mathrm{Mn} / \mathrm{Co}$ ratios of $0.1,0.3$ and 0.9 were obtained when maintaining the $\mathrm{Mn}\left(\mathrm{NO}_{3}\right)_{2} \cdot 4 \mathrm{H}_{2} \mathrm{O} / \mathrm{Co}\left(\mathrm{NO}_{3}\right)_{2} \cdot 6 \mathrm{H}_{2} \mathrm{O}$ feeding ratios of the precursors at $0.11,0.33$ and 0.92 , respectively. The
Table 1 Quantitative analysis of $\mathrm{Mn}, \mathrm{Cr}, \mathrm{Si}$ and $\mathrm{Co}$ in all samples determined

\begin{tabular}{lllrll}
\hline Samples & Si (wt\%) & Co $(w t \%)$ & $\mathrm{X}(\mathrm{wt} \%)$ & $\mathrm{X}^{b} / \mathrm{Co}$ & $(\mathrm{X}+\mathrm{Co}) / \mathrm{Si}$ \\
\hline CoSi & 68.4 & 31.5 & \multicolumn{1}{c}{-} & - & $0.46(0.5)$ \\
MnCoSi-0.1 & 67.8 & 29.3 & 2.90 & $0.1(0.11)^{a}$ & $0.48(0.5)$ \\
MnCoSi-0.3 & 66.9 & 25.5 & 7.60 & $0.3(0.33)$ & $0.49(0.5)$ \\
MnCoSi-0.9 & 68.6 & 16.6 & 14.80 & $0.9(0.92)$ & $0.46(0.5)$ \\
CrCoSi-0.1 & 67.5 & 29.1 & 3.40 & $0.11(0.11)$ & $0.48(0.5)$ \\
CrCoSi-0.3 & 68.3 & 24.7 & 6.80 & $0.28(0.33)$ & $0.46(0.5)$ \\
CrCoSi-0.9 & 66.3 & 17.5 & 16.10 & $0.92(0.92)$ & $0.50(0.5)$
\end{tabular}

${ }^{a}$ The nominal values are within brackets. ${ }^{b} \mathrm{X}$ represents $\mathrm{Mn}$ or $\mathrm{Cr}$ according to the sample name.

measured values of $\mathrm{X} / \mathrm{Co}$ and $(\mathrm{X}+\mathrm{Co}) / \mathrm{Si}$ ratios were found to be closed to the nominal ones, showing less than $5 \%$ variation.

This indicates that the changes observed during single-gas permeation measurements cannot be ascribed to the difference in the total concentration of binary metal oxides in the silica matrix, but to a variation of $\mathrm{X} / \mathrm{Co}$ molar ratio.

The formation of silica with different micro-structures upon the variation of $\mathrm{X} / \mathrm{Co}$ molar ratio was also confirmed by the measurement of the BET surface area by means of $\mathrm{N}_{2}$ adsorption-technique. We are aware that the $\mathrm{N}_{2}$-adsorption technique is not representative of the surface area accessible by $\mathrm{H}_{2}$ but can give information of the general texture of the membrane. ${ }^{22}$ The BET surface area of the CoSi sample was found to be $164 \mathrm{~m}^{2} \mathrm{~g}^{-1}$, a value that decreased to $155 \mathrm{~m}^{2} \mathrm{~g}^{-1}$ with an increase of $\mathrm{Mn} / \mathrm{Co}$ to 0.1 due to the densification of the sample.

A further increase of the Mn/Co molar ratio from 0.3 to 0.9 resulted in an increase of the BET surface area from $196 \mathrm{~m}^{2} \mathrm{~g}^{-1}$ to $235 \mathrm{~m}^{2} \mathrm{~g}^{-1}$, indicating the formation of more porous structures.

\section{Crystallization and phase information}

The XRD patterns at room temperature for the CoSi and XCoSi (X $=\mathrm{Mn}, \mathrm{Cr}$ ) powders are displayed in Fig. 3(a) and (b). The diffraction pattern of the CoSi powder exhibits reflections corresponding to the face centered cubic $F d 3 m$ spinel-type phase (ICCD-PDF-Nr: 01-080-1536) with a lattice parameter of 0.8084 $\mathrm{nm}$, indicating the presence of crystalline spinel $\mathrm{Co}_{3} \mathrm{O}_{4}$ phases into the silica matrix. Upon doping with $\mathrm{Mn}$ or $\mathrm{Cr}$, the cubic $F d 3 m$ spinel structure is retained and the diffraction peaks shift to lower angles. The shift to lower angles of diffractions peaks is an indication of the insertion of $\mathrm{Mn}$ and $\mathrm{Cr}$ ions into the lattice of the spinel $\mathrm{Co}_{3} \mathrm{O}_{4}$. This was also confirmed by the increase of the lattice parameter (see Table $\mathrm{S} 2 \dagger$ ) from $0.8084 \mathrm{~nm}$ to $0.8255 \mathrm{~nm}$ and $0.8263 \mathrm{~nm}$ with an increase in $\mathrm{Mn} / \mathrm{Co}$ and $\mathrm{Cr} / \mathrm{Co}$ molar ratios from 0 to 0.92 , respectively. The increase of the lattice parameter with the doping content can be well understood by considering the difference in ionic radii of $\mathrm{Co}, \mathrm{Mn}$ and $\mathrm{Cr}$ ions $\left(\mathrm{Co}^{2+}: 0.65 \mathrm{pm}, \mathrm{Co}^{3+}: 0.54 \mathrm{pm}, \mathrm{Mn}^{2+}: 0.67 \mathrm{pm}, \mathrm{Mn}^{3+}\right.$ : $0.65 \mathrm{pm}$ and $\left.\mathrm{Cr}^{3+}: 0.62 \mathrm{pm}\right)$. It is more likely that the substitution of $\mathrm{Co}^{3+}(0.54 \mathrm{pm})$ by larger $\mathrm{Cr}^{3+}(0.62 \mathrm{pm})$ and $\mathrm{Mn}^{3+}$ 

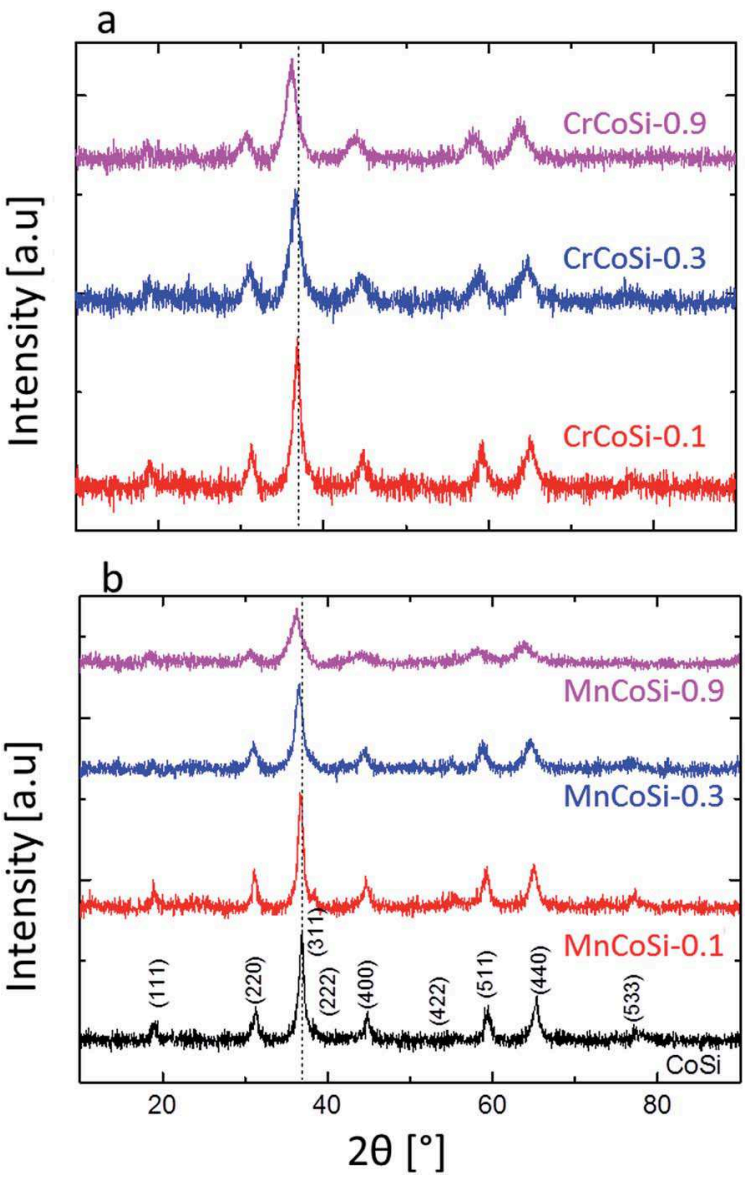

Fig. 3 XRD patterns of CoSi and XCoSi $(X=M n, C r)$ samples with different X/Co molar ratios. The background of the XRD patterns was subtracted using the Origin Pro 9 software.

$(0.65 \mathrm{pm})$ cations in the octahedral site of the spinel $\mathrm{Co}_{3} \mathrm{O}_{4}$ is responsible for the enlargement of the unit cell.

The average crystalline size of these nanoparticles was estimated using the Scherrer equation and reported in Table S2.† An obvious decrease of the crystalline size with increasing the $\mathrm{Mn}$ or Cr content was noticed. For example, the CoSi sample showed an average crystalline size of $9.31 \pm 0.5 \mathrm{~nm}$ that decreased to $3.68 \pm 0.8 \mathrm{~nm}$ and $4.5 \pm 1.0 \mathrm{~nm}$ for MnCoSi-0.9 and CrCoSi-0.9 samples, respectively. It is worth mentioning that no crystalline phases corresponding to $\mathrm{MnO}_{x}$ or $\mathrm{CrO}_{x}$ oxides were observed in the XRD patterns. However, as it will be later shown, the formation of amorphous species into the silica matrix cannot be ruled out.

\section{Morphological (TEM) analysis}

Fig. 4 shows representative bright-field (BF) TEM micrographs and the electron diffraction pattern of MnCoSi-0.1 powder. The BF micrographs show that the MnCoSi-0.1 sample is composed of nanocrystalline particles with diameter less than $10 \mathrm{~nm}$, in agreement with the XRD results. The nanocrystals appear not to be very well distributed in the silica matrix as some empty places and agglomeration of tiny crystals can be observed. A close examination of the selected area diffraction pattern (insert
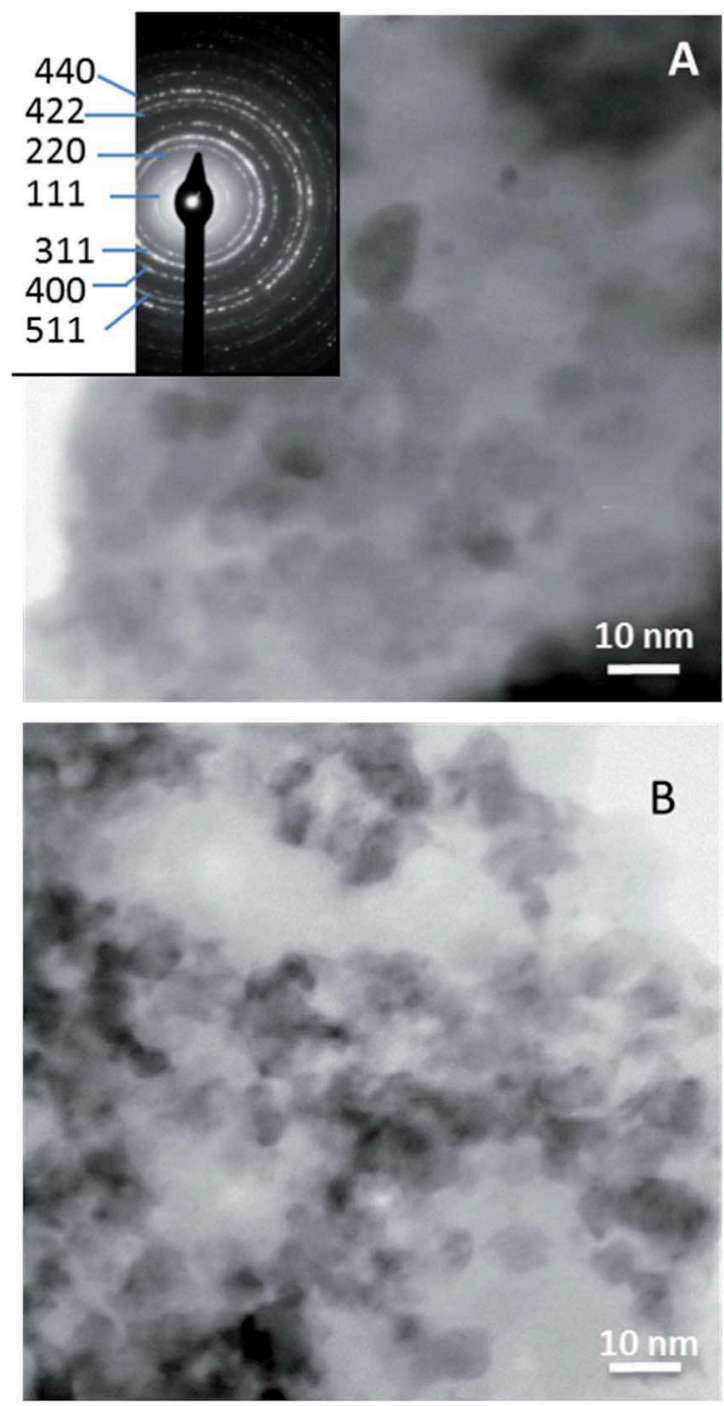

Fig. 4 XRD representative bright-field TEM images and electron diffraction pattern (insert) of the MnCoSi-0.1 sample of the sample (see Fig. $\mathrm{S} 2 \dot{\dagger})$.

in Fig. 4(a)) reveals a total of nine characteristic diffraction rings. As reported in Table $\mathrm{S} 3, \dagger$ the ratio of the diameter of the diffraction rings $\left(D_{1} / D_{\mathrm{i}}\right)$ was observed to be consistent with the ratio of $d$-spacing $\left(d_{1} / d_{\mathrm{i}}\right)$ obtained from the reflections corresponding to the face centered cubic $F d 3 m$ spinel-type $\mathrm{Co}_{3} \mathrm{O}_{4}$ phase (ICCD-PDF-Nr: 01-080-1536). These results confirm the nanocrystalline nature and the $F d 3 m$ face centered cubic symmetry of the nanoparticles. The EDX analysis of some selected nanoparticles from the TEM micrographs of MnCoSi0.1 (see Fig. S1†) only revealed the presence of Co, while Co and $\mathrm{Mn}$ were detected in the matrix of MnCoSi-0.1 powder. These results suggest that not only $\mathrm{Co}_{3} \mathrm{O}_{4}$ nanocrystals are present in the silica matrix of MnCoSi-0.1 powder but also some amorphous Co and Mn species, which were undetectable by XRD analysis. This is in agreement with the work of Esposito et al. ${ }^{23}$ who reported that beside nanocrystalline $\mathrm{Co}_{3} \mathrm{O}_{4}$ particles, amorphous $\mathrm{Co}^{2+}$ ions strongly bonded to the silica matrix were formed during the sol-gel preparation of CoSi powders. It is 
worth mentioning that XRD results have indicated an increase of the lattice parameter from $0.808 \mathrm{~nm}(\mathrm{CoSi})$ to $0.811 \mathrm{~nm}$ (MnCoSi-0.1). Therefore, the non-detection of Mn by analysing the nanoparticle of MnCoSi-0.1 powder might be explained by its relative low quantity that is under the detection limit of the EDX set-up.

\section{Chemical (XPS) analysis}

The possible variations in oxidation states of the elements Co, $\mathrm{Mn}$ and $\mathrm{Cr}$ in the prepared samples were assessed from XPS measurements by analyzing Co2p, Cr2p, Mn2p and Mn3s core shell spectra. The Co2p high-resolution spectra of the CoSi and CrCoSi powders with different $\mathrm{Cr} / \mathrm{Co}$ ratios are shown in Fig. 5.

The Co2p spectra consist of two main spin-orbital lines, $2 \mathrm{P}_{3 / 2}$ and $2 \mathrm{p}_{1 / 2}$, separated by about $15 \mathrm{eV} .^{24-26}$

The peak at 779.59-779.25 eV is assigned to $\mathrm{Co}^{3+}$ in octahedral sites, while the peak at 780.80-781.55 is attributed to $\mathrm{Co}^{2+}$ in tetrahedral sites of the spinel $\mathrm{Co}_{3} \mathrm{O}_{4} \cdot{ }^{25}$ The satellite peaks $\mathrm{S} 1$ and $\mathrm{S} 2$, located at 5-6 eV and 9-10 eV above the main Co2 $\mathrm{p}_{3 / 2}$ line, are associated with Co cations having a valence of +2 and +3 , respectively. ${ }^{26}$ A similar deconvolution was done for MnCoSi powders and quantitative details regarding the peak fittings are summarized in Table S4. $\dagger$ For all the samples it can be seen that the satellite peak S2 is much weaker than S1, indicating a predominance of $\mathrm{Co}^{2+}$ ions over $\mathrm{Co}^{3+}$. The fitted $\mathrm{Co}^{3+} / \mathrm{Co}^{2+}$ value for the CoSi is 0.80 , which is far from the expected value, 2, for stoichiometric $\mathrm{Co}_{3} \mathrm{O}_{4}$ but in agreement with the value, 0.9, reported for sol-gel made $\mathrm{CoO}_{x}-\mathrm{SiO}_{2}$ xerogels. ${ }^{8}$ This low

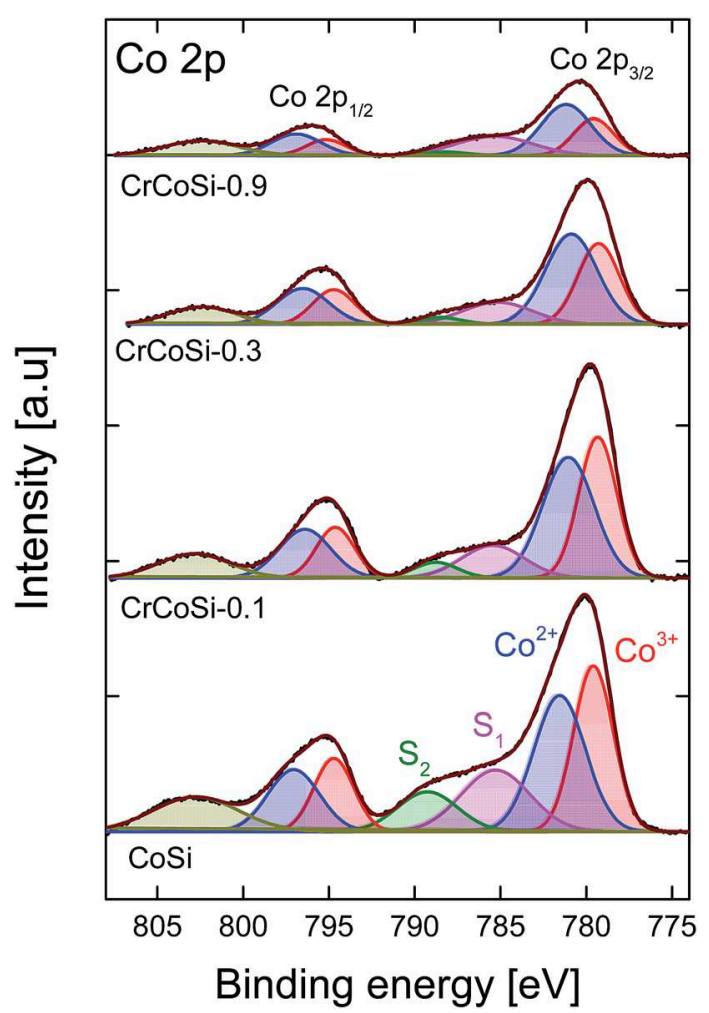

Fig. 5 Co2p spectra recorded from CoSi and CrCoSi samples with different $\mathrm{Cr} / \mathrm{Co}(\mathrm{Cr} / \mathrm{Co}=0.1,0.3,0.9)$ molar ratios.
$\mathrm{Co}^{3+} / \mathrm{Co}^{2+}$ value confirms the presence of others amorphous $\mathrm{Co}^{2+}$ species besides the crystalline $\mathrm{Co}_{3} \mathrm{O}_{4}$ spinel, which is agreement with TEM results. The fitted $\mathrm{Co}^{3+} / \mathrm{Co}^{2+}$ ratio is noted to decrease from 0.73 to 0.40 and from 0.68 to 0.31 as the $\mathrm{Mn} / \mathrm{Co}$ molar ratio increase from 0.1 to 0.9 , respectively. The decrease of $\mathrm{Co}^{3+} / \mathrm{Co}^{2+}$ ratio with increasing doping content confirms the information obtained from XRD measurements i.e. the substitution of $\mathrm{Co}^{3+}$ by larger $\mathrm{Mn}$ and $\mathrm{Cr}$ ions.

The Mn3s and Mn2p high resolution spectra, Fig. 6(a) and (b), were analyzed to determine the oxidation state of Mn. The doublet of the Mn3s peak is a result of the parallel spin coupling between electrons in the $3 \mathrm{~s}$ and $3 \mathrm{~d}$ orbital and the energy separation between the two peaks is closely related to the mean oxidation state of $\mathrm{Mn}^{26}$ The splitting widths and the mean oxidation state of Mn ions are provided in Table S5. $\dagger$ The splitting width values were obtained from the deconvolution of Mn3s core shell spectra, Fig. 6(a), while the mean oxidation state of $\mathrm{Mn}$ ions were determined from a linear relationship between the splitting width and the mean oxidation state of $\mathrm{Mn}$ obtained from the literature. ${ }^{27}$ The Mn3s peak splitting width decreased from 5.73 to 5.42 with an increase in Mn content. The decrease of the peak splitting width corresponds to an increase of the mean Mn oxidation state from 2.10 to 2.75, i.e. Mn exist in MnCoSi samples as $\mathrm{Mn}^{2+}$ and $\mathrm{Mn}^{3+}$ ions.

The deconvolution of the Mn2 $\mathrm{p}_{3 / 2}$ peak, Fig. 6(b), shows the presence of two components $\mathrm{Mn}^{2+}$ and $\mathrm{Mn}^{3+}$, in agreement with the oxidation states predicted from resolved Mn3s spectra. The fitted $\mathrm{Mn}^{3+} / \mathrm{Mn}^{2+}$ ratio increased from 0.55 to 1.03 with the increase in $\mathrm{Mn}$ content, indicating the formation of $\mathrm{Mn}^{3+}$ ions at the expense of $\mathrm{Mn}^{2+}$. The presence of $\mathrm{Mn}^{2+}$ in MnCoSi samples is not surprising when considering the nature of the starting precursor: $\mathrm{Mn}\left(\mathrm{NO}_{3}\right)_{2} \cdot 4 \mathrm{H}_{2} \mathrm{O}$. We believe that amorphous $\mathrm{Mn}^{2+}$ ions are dispersed in the silica matrix and only $\mathrm{Mn}^{3+}$ ions interact with $\mathrm{Co}_{3} \mathrm{O}_{4}$ nanoparticles, which result to an increase of the lattice parameter as Mn content increased. This

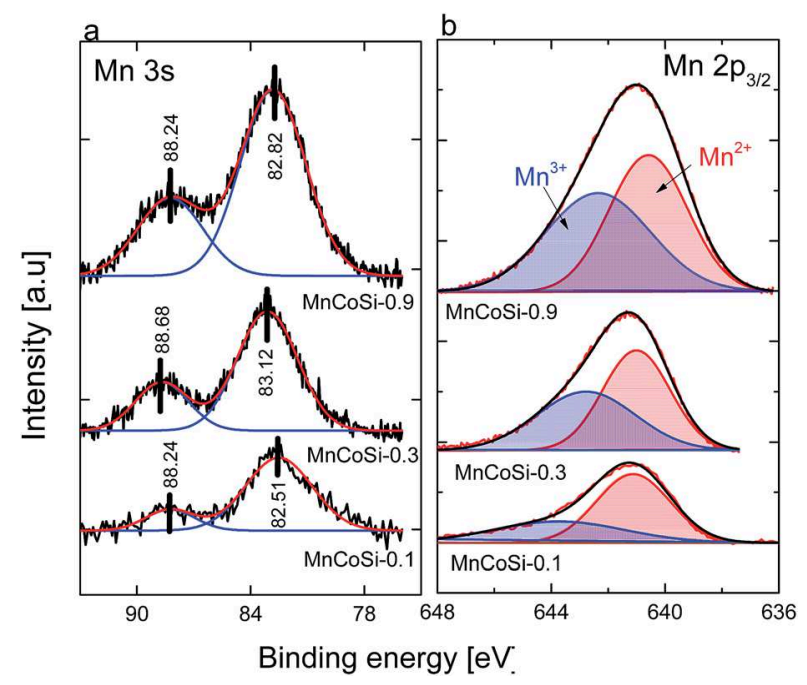

Fig. 6 XPS analysis of MnCoSi samples with different $\mathrm{Mn} / \mathrm{Co}(\mathrm{Mn} / \mathrm{Co}=$ $0.1,0.3,0.9)$ molar ratios: (a) fitted Mn3s photoelectron peaks, (b) fitted $\mathrm{Mn} 2 \mathrm{p} 3 / 2$ photoelectron peaks. 
assumption is supported by two explanations: first, the substitution of $\mathrm{Co}^{2+}$ by $\mathrm{Mn}^{2+}$ in the tetrahedral site of the spinel $\mathrm{Co}_{3} \mathrm{O}_{4}$ can be ruled out as the difference in ionic radii between $\mathrm{Co}^{2+}(0.65 \mathrm{pm})$ and $\mathrm{Mn}^{2+}(0.67 \mathrm{pm})$ is negligible when considering $\mathrm{Co}^{3+}(0.54 \mathrm{pm})$ and $\mathrm{Mn}^{3+}(0.65 \mathrm{pm})$. Second, in $\mathrm{Mn}_{x} \mathrm{Co}_{3-x} \mathrm{O}_{4}(0<x<3)$ systems, the face centered cubic $F d 3 m$ spinel-type solid has been reported to be formed in the compositional range of $x<1.5$ (i.e. $\mathrm{Mn} / \mathrm{Co}<1$ ) with a lattice parameter increasing from $0.807 \mathrm{~nm}(x=0)$ to $0.8321 \mathrm{~nm}$ $(x=1.5)$ due to the substitution of $\mathrm{Co}^{3+}$ by $\mathrm{Mn}^{3+} \cdot{ }^{25}$ The substitution of $\mathrm{Co}^{2+}$ by $\mathrm{Mn}^{2+}$ in the tetrahedral sites have been reported to occur only in the Mn-rich region $(x>1.7$ i.e. $\mathrm{Mn} / \mathrm{Co}$ $>1.3$ ), which exhibit a tetragonal $I 4_{1}$ /amd spinel type phase. ${ }^{25}$ In this work, all MnCoSi samples (Mn/Co: 0.1-0.9) showed a face centered cubic $F d 3 m$ spinel-type phase with increasing lattice parameter from $0.808 \mathrm{~nm}(\mathrm{Mn} / \mathrm{Co}=0)$ to $0.825(\mathrm{Mn} / \mathrm{Co}$ $=0.9$ ). Fig. 7 shows the Cr2p spectra for CrCoSi powders with different $\mathrm{Cr} / \mathrm{Co}$ molar ratios.

The spectra were resolved in two peaks with binding energy of $576.73 \mathrm{eV}$ and $578.2 \mathrm{eV}$ corresponding to $\mathrm{Cr}^{3+}$ and $\mathrm{Cr}^{6+}$, respectively. ${ }^{28}$ The fitted $\mathrm{Cr}^{6+} / \mathrm{Cr}^{3+}$ ratio, as shown in Table S5, $\dagger$ decreased from 0.68 to 0.52 with an increase in Cr content. As $\mathrm{Cr}^{6+}$ ions have been reported to be surface-only species, ${ }^{29}$ we believe that the decrease in $\mathrm{Co}^{3+} / \mathrm{Co}^{2+}$ ratio can only be ascribed to the substitution of $\mathrm{Co}^{3+}$ by $\mathrm{Cr}^{3+}$ ions. However, as for MnCoSi samples, the presence of amorphous $\mathrm{Cr}^{3+}$ species in the silica matrix cannot be ruled out as $\mathrm{Cr}\left(\mathrm{NO}_{3}\right)_{3} \cdot 9 \mathrm{H}_{2} \mathrm{O}$ was used as starting precursor.

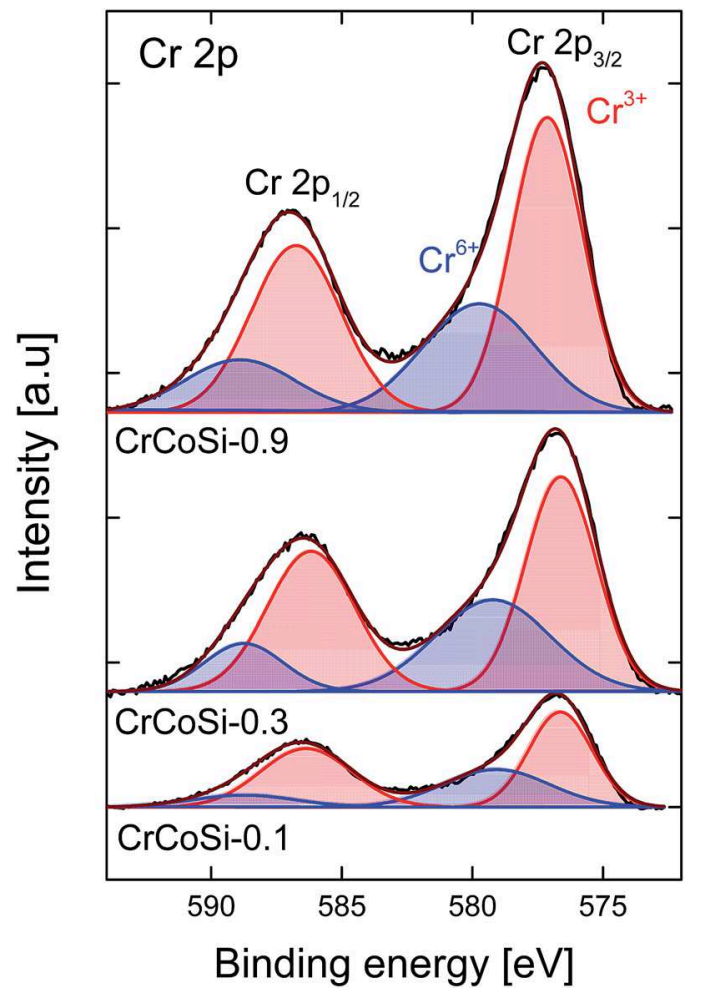

Fig. 7 Cr2p spectra recorded from CrCoSi samples with different $\mathrm{Cr} / \mathrm{Co}(\mathrm{Cr} / \mathrm{Co}=0.1,0.3,0.9)$ molar ratios.

\section{Structural (FTIR) analysis}

Fourier transform infrared spectroscopy was performed to assess the changes in the silica matrix induced by the variation in composition of binary $\mathrm{Cr}-\mathrm{Co}$ and Mn-Co oxides. The FTIR spectra of CoSi and XCoSi (X = Mn, Cr) samples in the typical region of 900-1300 $\mathrm{cm}^{-1}$ are displayed in Fig. 8(a) and (b). Upon doping with single cobalt oxide and binary $\mathrm{Mn}-\mathrm{Co}$ and $\mathrm{Cr}-\mathrm{Co}$ oxides some variations in the shape and the frequency of the $\mathrm{Si}-\mathrm{O}-\mathrm{Si}$ asymmetric stretching band can be observed. This indicates that the insertion of these oxides, with different $\mathrm{X} / \mathrm{Co}$ molar ratios, in the silica matrix induces changes in the structure of the siloxane network. To get more insights into these chemical changes, the $\mathrm{Si}-\mathrm{O}-\mathrm{Si}$ absorption band of CoSi and MnCoSi samples has been deconvoluted by means of five Gaussian contributions as shown in Fig. S3. $\dagger$ The peak at $950 \mathrm{~cm}^{-1}$ (1) represents the $\mathrm{Si}-\mathrm{OH}$ bending vibration and the four other peaks $(2-5)$ are attributed to $\mathrm{Si}-\mathrm{O}-\mathrm{Si}$ stretching modes with different bond angles.

According to the literature, ${ }^{30,31}$ the peak centered at around $1042 \mathrm{~cm}^{-1}$ is assigned to $\mathrm{Si}-\mathrm{O}-\mathrm{Si}$ small rings, while the peaks centered at around 1079, 1150 and $1220 \mathrm{~cm}^{-1}$ are attributed to $\mathrm{Si}-\mathrm{O}-\mathrm{Si}-\mathrm{OH}$ opened small rings with a terminal $\mathrm{OH}-$ group, $\mathrm{Si}-\mathrm{O}-\mathrm{Si}$ larger rings and $\mathrm{Si}-\mathrm{O}-\mathrm{Si}-\mathrm{OH}$ opened larger rings with a terminal $\mathrm{OH}-$ group, respectively. Smaller rings refer to the stretching of $\mathrm{Si}-\mathrm{O}-\mathrm{Si}$ bonds in a network structure with bond angles $\leq 144^{\circ}$, while larger rings refer to the stretching of $\mathrm{Si}-\mathrm{O}-\mathrm{Si}$ bonds in a cage structure with bond angles $\geq 150^{\circ} .{ }^{32}$

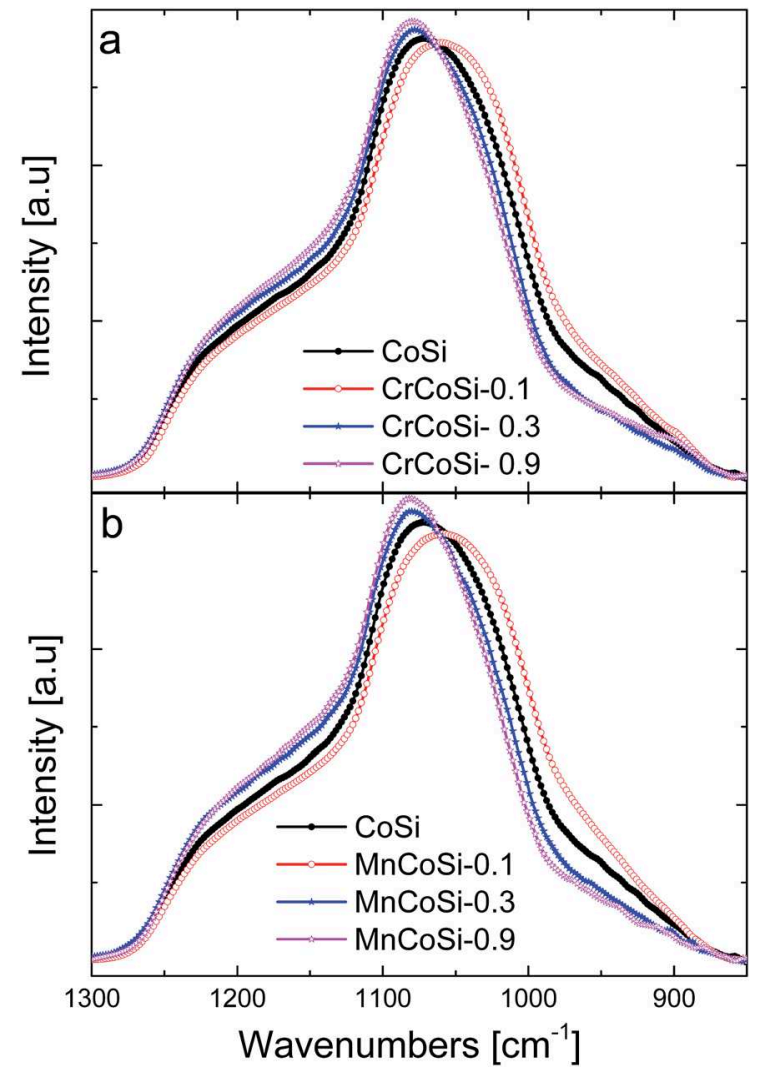

Fig. 8 FTIR spectra of all samples in the region $850-1300 \mathrm{~cm}^{-1}$. 
This means that, the smaller the bond angle, the higher density of the network and the lower the peak wavenumber would be. Fig. 9(a) displays the frequency shift of the most intense peak corresponding to $\mathrm{Si}-\mathrm{O}-\mathrm{Si}$ small rings (peak 2 in Fig. 9) as a function of the metal oxide composition.

The CoSi sample showed a $\mathrm{Si}-\mathrm{O}-\mathrm{Si}$ vibrational mode at $1042 \mathrm{~cm}^{-1}$, which decreases to $1035 \mathrm{~cm}^{-1}$ as the X/Co $(\mathrm{X}=\mathrm{Cr}$ or $\mathrm{Mn}$ ) molar ratio increases to 0.10 . This shift to lower wavenumbers indicates a decrease in the bonding angle i.e. an improvement of density of the silica network, which is in line with the gas permeation results. Further increase of the X/Co ratio enables a shift of the $\mathrm{Si}-\mathrm{O}-\mathrm{Si}$ peak to higher wavenumbers. For example, samples with X/Co molar ratios of 0.3 and 0.9 show a vibrational frequency value higher than that of the single CoSi sample because of a less dense silica network. More information on the changes in the silica

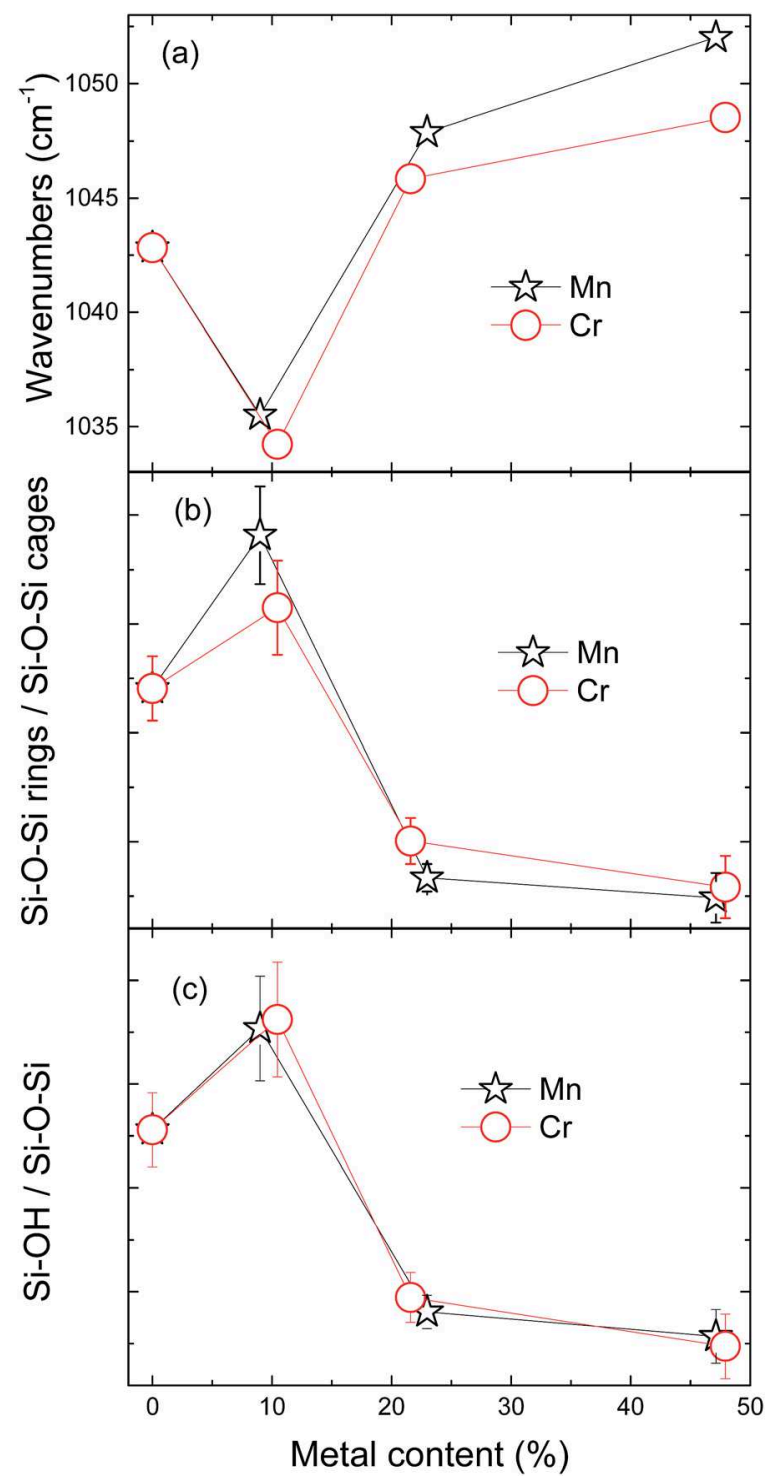

Fig. 9 (a) Frequency shift of the $\mathrm{Si}-\mathrm{O}-\mathrm{Si}$ small ring and variation of the peak area ratios (b) $\mathrm{Si}-\mathrm{O}-\mathrm{Si}$ rings/ $\mathrm{Si}-\mathrm{O}-\mathrm{Si}$ cages and (c) $\mathrm{Si}-\mathrm{OH} / \mathrm{Si}-\mathrm{O}-$ $\mathrm{Si}$ as a function of the X/Co (X: Mn, Co) molar ratio. structure was also obtained by investigating the evolution of the "small rings/large rings" area ratio i.e. the variation of the peak area $[(2+3) /(4+5)]$ ratio as a function of the doping content (Fig. 9(b)). The binary XCoSi-0.1 samples show a higher value of the "Ring/Cage" ratio compare with that of the single oxide CoSi sample. However, this ratio drastically decrease to very low values for XCoSi-0.3 and XCoSi-0.9 samples, indicating an increase of the concentration of large siloxane rings. These results are in line with the behavior of the $\mathrm{H}_{2} / \mathrm{N}_{2}$ permeance ratio as shown in Fig. 2(c).

Fig. 9(c) displays the evolution of the silanol-to-siloxane peak area ratio as a function of $\mathrm{X}$ content. This corresponds directly to the trends observed in Fig. 9(b) and 2(c). Increasing the X/Co content from 0.1 to 0.9 enables a decrease of the concentration of $\mathrm{Si}-\mathrm{OH}$ groups at the expense of $\mathrm{Si}-\mathrm{O}-\mathrm{Si}$ groups. Therefore, the decrease of the $\mathrm{H}_{2} / \mathrm{N}_{2}$ permeation ratio can only be ascribed to the formation of larger siloxane rings, which is more likely to occur via condensation reactions. Note that binary XCoSi samples with $\mathrm{X} / \mathrm{Co}$ molar ratio of 0.1 display a higher concentration of $\mathrm{Si}-\mathrm{OH}$ compared to the single CoSi sample. This is not surprising as the presence of $\mathrm{Si-OH}$ groups in the silica network is well-known to induce molecular sieve structures with narrow pore sizes.

\section{Conclusions}

In this study, the sol-gel method was used for the preparation of several binary Co-X oxides-doped silica membranes (X: Mn, $\mathrm{Cr}$ ) with different $\mathrm{X} / \mathrm{Co}$ molar ratio (X/Co: 0.1, 0.3, 0.9) while keeping constant the total metal-to-silicon molar ratio $((\mathrm{X}+$ $\mathrm{Co}) / \mathrm{Si}=0.5)$. Single gas permeation tests were performed at $200{ }^{\circ} \mathrm{C}$ to determine the effect of binary Co-X oxide composition on the amorphous silica network. In addition, several characterization techniques such as XPS, XRD, FTIR and TEM were used to evaluate the changes in the silica matrix induced by the variation in composition of these binary oxides. The $\mathrm{H}_{2} / \mathrm{N}_{2}$ permeance ratio decreased for more than one order of magnitude with an increase in X/Co molar ratio from 0.1 to 0.9 due to the formation of large pore sizes. On the other hand, membranes prepared with the X/Co molar ratio of 0.1 showed $\mathrm{a}_{2} / \mathrm{N}_{2}$ permeance ratio, which was approximately twice higher than that of the single cobalt oxide-doped silica membrane (CoSi), indicating a densification of the silica network. Upon doping with $\mathrm{Mn}$ and $\mathrm{Cr}$, the lattice parameter significantly increased due to the substitution of $\mathrm{Co}^{3+}$ by larger cations $\mathrm{Mn}^{3+}$ and $\mathrm{Cr}^{3+}$ in octahedral sites of the spinel $\mathrm{Co}_{3} \mathrm{O}_{4}$. This resulted to the formation of $\mathrm{Mn}_{x} \mathrm{Co}_{3-x} \mathrm{O}_{4}$ and $\mathrm{Cr}_{x} \mathrm{Co}_{3-x} \mathrm{O}_{4}$ oxide nanocrystals within the silica matrix. However, the presence of amorphous (Co, Mn and Cr) species was also demonstrated. The formation of larger pore sizes at high $\mathrm{X}$ content was ascribed to the formation of bigger siloxane rings via condensation reactions. The presence of narrow pore sizes at low X content was attributed to the high concentration of silanol groups, more likely influenced by the concentration of amorphous species ( $\mathrm{Mn}$, and $\mathrm{Cr}$ ) in the silica matrix. 


\section{Acknowledgements}

One of the authors, Patrick H. Tchoua Ngamou, acknowledges a Fellowship of the Alexander von Humboldt ( $\mathrm{AvH})$ Foundation for his postdoctoral stay in Germany.

\section{References}

1 J. Zang, Y. Ding, Y. Pei, J. Liu, R. Lin, L. Yan, T. Liu and Y. Lu, React. Kinet., Mech. Catal., 2014, 112, 159.

2 C.-C. Lin, Y. Guo and J. Vela, ACS Catal., 2015, 5, 1037.

3 R. Xie, C. Wang, L. Xia, H. Wang, T. Zhao and Y. Sun, Catal. Lett., 2014, 144, 516.

4 C. Cantalini, M. Post, D. Buso, A. Guglielmi and A. Martucci, Sens. Actuators, B, 2005, 108, 184.

5 O. A. Fouad, G. A. M. Ali, M. A. I. El-Erian and S. A. Makhlouf, Nano, 2012, 7, 1.

6 R. Igi, T. Yoshioka, Y. H. Ikuhara, Y. Iwamoto and T. Tsuru, J. Am. Ceram. Soc., 2008, 91, 2975.

7 D. Uhlmann, S. Smart and J. C. D. da Costa, Sep. Purif. Technol., 2010, 76, 171-178.

8 L. Liu, D. K. Wang, D. L. Martens, S. Smart, E. Strounina and J. C. D. da Costa, RSC Adv., 2014, 4, 18862-18870.

9 L. Liu, D. K. Wang, D. L. Martens, S. Smart and J. C. D. da Costa, J. Membr. Sci., 2015, 475, 425-432.

10 V. Boffa, G. Magnacca, L. B. Jorgensen, A. Wehner, A. Doernhoefer and Y. Yue, Microporous Mesoporous Mater., 2013, 179, 242-249.

11 D. Uhlmann, S. Smart and J. C. D. da Costa, J. Membr. Sci., 2011, 380, 48-54.

12 J. Wang and T. Tsuru, J. Membr. Sci., 2011, 369, 13-19.

13 A. Darmawan, S. Smart, A. Julbe and J. C. D. da Costa, Materials, 2011, 4, 448-456.

14 Y.-F. Han, F. Chen, Z. Zhong, K. Ramesh, L. Chen and E. Widjaja, J. Phys. Chem. B, 2006, 110, 24450-24456.

15 X. Z. Zhang, Y. H. Yue and Z. Gao, Catal. Lett., 2002, 83, 1925.
16 B. Ballinger, J. Motuzas, S. Smart and J. C. D. da Costa, Palladium cobalt binary doping of molecular sieving silica membranes, J. Membr. Sci., 2014, 451, 185-191.

17 B. Ballinger, J. Motuzas, S. Smart and J. C. D. da Costa, J. Membr. Sci., 2015, 489, 220-226.

18 A. Darmawan, J. Motuzas, S. Smart, A. Julbe and J. C. D. da Costa, J. Membr. Sci., 2015, 474, 32-38.

19 N. Bahlawane, P. H. T. Ngamou, V. Vannier, T. Kottke, J. Heberle and K. Kohse-Hoeinghaus, Phys. Chem. Chem. Phys., 2009, 11, 9224-9232.

20 T. van Gestel, F. Hauler, M. Bram, W. A. Meulenberg and H. P. Buchkremer, Sep. Purif. Technol., 2014, 121, 20-29.

21 M. C. Biesinger, B. P. Payne, A. P. Grosvenor, L. W. M. Lau, A. R. Gerson and R. S. C. Smart, Appl. Surf. Sci., 2011, 257, 2717-2730.

22 K. Morishige, J. Phys. Chem. C, 2011, 115, 9713-9718.

23 S. Esposito, M. Turco, G. Ramis, G. Bagnasco, P. Pernice, C. Pagliuca, M. Bevilacqua and A. Aronne, J. Solid State Chem., 2007, 180, 3341-3350.

24 H. Bordeneuve, C. Tenailleau, S. Guillemet-Fritsch, R. Smith, E. Suard and A. Rousset, Solid State Sci., 2010, 12, 379-386.

25 A. Restovic, E. Rios, S. Barbato, J. Ortiz and J. L. Gautier, J. Electroanal. Chem., 2002, 522, 141-151.

26 W. Wei, W. Chen and D. G. Ivey, Chem. Mater., 2008, 20, 1941-1947.

27 B. Djurfors, J. N. Broughton, M. J. Brett and D. G. Ivey, Acta Mater., 2005, 53, 957-965.

28 J. Chen, X. Zhang, H. Arandiyan, Y. Peng, H. Chang and J. Li, Catal. Today, 2013, 201, 12-18.

29 J. Sloczynski, J. Janas, T. Machej, J. Rynkowski and J. Stoch, Appl. Catal., B, 2000, 24, 45-60.

30 A. Milella, M. Creatore, M. C. M. van de Sanden and N. Tomozeiu, J. Optoelectron. Adv. Mater., 2006, 8, 2003-2010.

31 A. Milella, M. Creatore, M. A. Blauw and M. C. M. V. de Sanden, Plasma Processes Polym., 2007, 4, 621-628.

32 A. Grill and D. A. Neumayer, J. Appl. Phys., 2003, 94, 66976707. 